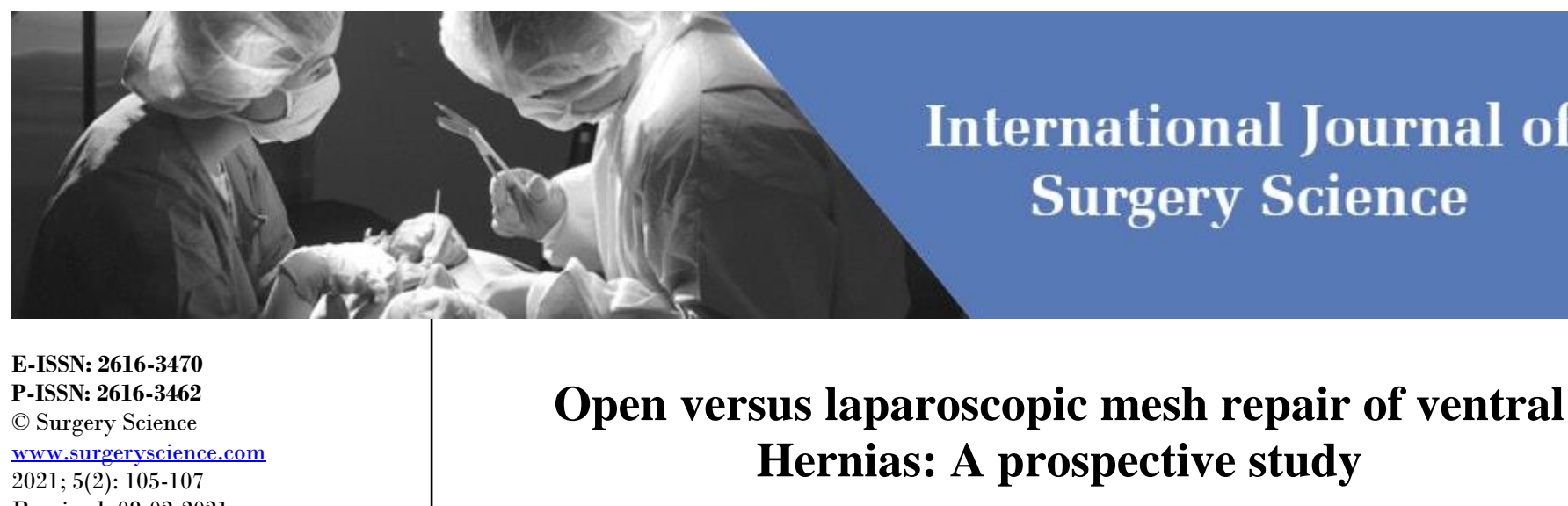

Received: 08-02-202

Accepted: 26-03-2021

Dr. Santhosh Urs KS

General Surgeon, MGM Hospital, Mudigere Taluk, Chikmagalur,

Karnataka, India

Dr. Niranjan Murthy General Surgeon, Ashraya Hospital, Chikmagalur, Karnataka, India

\section{Dr. Kavana D Rao}

Department of ENT, SNMC, Bagalkot, Karnataka, India
Corresponding Author: Dr. Niranjan Murthy General Surgeon, Ashraya Hospital, Chikmagalur,

Karnataka, India

\section{Dr. Santhosh Urs KS, Dr. Niranjan Murthy and Dr. Kavana D Rao}

DOI: https://doi.org/10.33545/surgery.2021.v5.i2b.689

\section{Abstract}

Ventral hernia refer to facial defects of the anterolateral abdominal wall through which intermittent or continuous protrusion of preperitoneal fat, intestinal contents, or rarely, an abdominal organ may occur. they are either congenital or acquired. It includes incisional hernias, paraumbilical hernias, umbilical hernia, epigastric hernias and spigelian hernias. Data was collected from Patients admitted with ventral hernia with the help of a proforma containing relevant history, clinical examination, appropriate investigations and surgical details.

The study was carried out with ethical clearance by the institutional ethics committee and in conformity with the guidelines for medical research laid out by ICMR and Helsinki declaration.

In our study we observed that the mean duration of surgery in open group was $75.8+/-30.7$ min and in laparoscopic group was $77.3+/-22.4 \mathrm{~min}$. Both the groups didn't differ with respect the duration of surgery. In our study we observed that mean duration of time taken to return to work (RTW) was $24.8+/$ 65 and 11.2+/-3.5 days in open and laparoscopic groups respectively. This observation was statistically significant with $\mathrm{p}$ value $<0.001$

Keywords: Laparoscopic mesh repair, ventral hernias, open mesh repair

\section{Introduction}

A hernia is a protrusion of visceral contents through the abdominal wall. There are two key components of a hernia. The first is the defect itself, namely the size and location of the defect. The second component is the hernia sac, which is protrusion of peritoneum through the defect. The hernia sac may contain abdominal contents such as omentum, small intestine, colon or bladder, or the sac may be empty ${ }^{[2]}$.

Ventral hernia refer to facial defects of the anterolateral abdominal wall through which intermittent or continuous protrusion of preperitoneal fat, intestinal contents, or rarely, an abdominal organ may occur, they are either congenital or acquired [2]. It includes incisional hernias, paraumbilical hernias, umbilical hernia, epigastric hernias and spigelian hernias ${ }^{[2]}$. In adults, more than $80 \%$ of ventral hernias result from previous surgery hence the term incisional hernias. They have been reported to occur after $0-26 \%$ of abdominal procedure. Although these hernias mostly become clinically manifest between 2 years and 5 years after surgery, studies have shown that, the process starts within the first postoperative month ${ }^{[2]}$.

Midline hernia occurring through linea alba abutting superiorly or inferiorly on the umbilicus is called as the para umbilical hernia ${ }^{[3]}$. They are generally acquired lesions. If the defect is small it can be repaired surgically. But large hernias with wide openings are difficult to repair surgically and should be treated with synthetic mesh repair. Epigastric hernia protrude through linea alba above the umbilicus $[3,4,5]$. Approximately $5 \%$ of the populations have epigastric hernias. Symptomatic epigastric hernia require surgery, incarceration of extraperitoneal fat is the pathology which is content of epigastric hernia. There is no sac, hence no bowel or omentum get stuck. Most of the spigelian hernias are acquired and requires surgery as the chances of intestinal obstruction is high ${ }^{[3,4,5]}$.

There are various types of repairs proposed for ventral hernias, of which the mesh repair has become most popular and acceptable. In this modern era of surgery, most of the emphasis is made on decreasing the hospital stay of the patient and also decreasing the postoperative morbidity and importance is given to cosmesis. 
Hence Laparoscopic surgery has gained paramount importance due to its minimally invasive technique, decreased hospital stay and also better cosmesis. There is continued debate as to the role of laparoscopy in ventral hernia repair, although laparoscopic repair has become increasingly popular, its outcomes need further evaluation.

\section{Methodology}

Data was collected from Patients admitted with ventral hernia with the help of a proforma containing relevant history, clinical examination, appropriate investigations and surgical details.

The study was carried out with ethical clearance by the institutional ethics committee and in conformity with the guidelines for medical research laid out by ICMR and Helsinki declaration.

30 consecutive adult patients with age above 18 years who underwent laparoscopic and 30 consecutive adult patients with age above 18 years who underwent open mesh repair of ventral hernias in Department of Surgery were part of this study.

\section{Preoperative Evaluation}

All patients who participated in this study were evaluated pre operatively with detailed history, clinical examination and relevant investigations including biochemical, serological and imaging modalities (as necessary).

\section{Preoperative Preparation}

All patients underwent Preanaesthetic checkup and prior informed written consent was taken. Patients were kept NPO for 6 to 8 hours. Mechanical bowel preparation was given for few selected patients. A dose of prophylactic antibiotic was administered before induction of anesthesia according to the institutional protocol.

\section{Selection of Type of Procedure}

Patients were selected for the procedure, either laparoscopic repair or open repair based on patients choice, surgeons preference and patients fitness for general anesthesia.

\section{Open surgical procedure}

Patients who were in open surgical group underwent the surgical procedure under either spinal (majority), spinal plus epidural or general anesthesia. Nasogastric tube and Foley's catheter were inserted in few cases according to the requirement. After induction patients were placed in supine position, parts painted and draped. The choice of skin incision was made according to the site and size of the defect, type of hernia and surgeons preference. After identifying the hernia sac, if there were no adhesions, the sac was dissected off the tissues and reduced into the peritoneal cavity.

When there were adhesions, sac was opened and contents were released and reduced. Once hernia is reduced, a polypropylene mesh is placed either in the preperitoneal, retromuscular, onlay or in the intraperitoneal position depending on the surgeon preference. The mesh is fixed at its four corners with nonabsorbable prolene sutures and along the sides. Suction drain was placed in some cases depending on the requirements according to the operating surgeon. Then subcutaneous tissue closed with absorbable sutures and skin closed with staples or non-absorbable sutures.

\section{Laparoscopic procedure}

All laparoscopic repairs were performed under general anesthesia. Nasogastric tube and Foley's catheter were inserted in few cases according to the requirement.

Patient is positioned supine without any tilt. The operating surgeon stands to the left of the patient with the camera assistant on his right or left depending on the location of hernia and the scrub nurse stands to the left side of the patient caudally with instrument table.

After painting and draping pneumoperitoneum is established by open Hasson's technique. First a $10 \mathrm{~mm}$ camera port is placed and with carbon dioxide insufflation the intraabdominal pressure is maintained at 12 to $15 \mathrm{~mm} \mathrm{Hg}$. Additional $5 \mathrm{~mm}$ (working) ports are placed depending on the type of hernia under direct vision, usually for midline hernias one $5 \mathrm{~mm}$ port is placed in the left lumbar region, and the other working port is placed in the left iliac region along the anterior auxiliary line.

Defect is delineated, defect size estimated to know the size of mesh to be placed. Wherever needed Adhesiolysis was done using sharp dissection or monopolar diathermy or harmonic scalpel.

The area to be covered by the mesh is marked after the pneumoperitoneum is released and the sites for transracial sutures were marked orienting the defect at its center. The mesh is inserted through the $10 \mathrm{~mm}$ port using a reducer.

Mesh is opened intraperitoneally and anchored to the anterior abdominal wall using absorbable tackers, fired using a specialized gun devise in all the cases. And in few cases the mesh is prepared with delayed absorbable PDS sutures in each corners of the mesh and anchored to anterior abdominal wall using a Cobbler needle and tackers were fired. After confirming haemostasis, the ports are withdrawn under vision. $10 \mathrm{~mm}$ port is closed with 2-0 polyglactin. Skin closed with either 3-0 Poliglecaprone or nylon sutures. In all cases a flexible, sterile, composite Physiomesh was used Tackers used in our patients were spiral helix shaped, absorbable. Each fixation device consists of 25 absorbable tacks and the trocar diameter of the fixation device is $5 \mathrm{~mm}$.

\section{Results}

Table 1: Association between Anesthesia and Surgery $(\mathrm{N}=60)$

\begin{tabular}{|c|c|c|c|}
\hline Anesthesia & Open $(\mathbf{n}=\mathbf{3 0})$ & Laparoscopic $(\mathbf{n}=\mathbf{3 0})$ & P Value \\
\cline { 1 - 3 } GA & $3(10.0)$ & $30(100.0)$ & \multirow{2}{*}{$<0.001$} \\
\hline Spinal & $21(70.0)$ & $0(0.0)$ & \\
\hline SA+EA & $6(20.0)$ & $0(0.0)$ & \\
\hline
\end{tabular}

In the study it was observed that, $70 \%$ of patients in open repair group underwent surgery under Spinal anesthesia, 20\% under Spinal and Epidural combined, 3\% under General anesthesia. Where as in all the subjects in laparoscopic group the surgery was performed under general anesthesia. This observation was statistically significant with $\mathrm{p}$ value of 0.001

Table 2: Association between Mesh Position and Surgery $(\mathrm{N}=60)$

\begin{tabular}{|c|c|c|c|}
\hline Mesh Position & Open $(\mathbf{n}=\mathbf{3 0})$ & Laparoscopic $(\mathbf{n}=\mathbf{3 0})$ & \multirow{2}{*}{ P Value } \\
\hline Preperitoneal & $17(56.7)$ & $0(0.0)$ & \\
\cline { 1 - 3 } Retromuscular & $9(30.0)$ & $0(0.0)$ & \multirow{2}{*}{0.001} \\
\hline Onlay & $2(6.7)$ & $0(0.0)$ & \\
\hline Intraperitoneal & $2(6.7)$ & $30(100.0)$ & \\
\hline
\end{tabular}

In the study group who underwent open repair it was observed that in $56.7 \%$ subjects mesh was placed Preperitoneally, in 30\% mesh was placed Retromuscularly, in $6.7 \%$ mesh was placed both onlay and Intraperitoneally. Whereas all the subjects in laparoscopic group mesh was placed intraperitoneally. This observation was statistically significant with $p$ value of 0.001 
Table 3: Association between Intraoperative Complications and Surgery

\begin{tabular}{|c|c|c|c|}
\hline Intraoperative Complications & $\begin{array}{c}\text { Open } \\
(\mathbf{n = 3 0})\end{array}$ & $\begin{array}{c}\text { Laparoscopic } \\
(\mathbf{n = 3 0 )}\end{array}$ & P Value \\
\hline None & $24(80.0)$ & $22(73.3)$ & \multirow{2}{*}{0.411} \\
\hline Haemorrhages & $5(16.7)$ & $8(26.7)$ & \\
\hline Bowel Injury & $1(3.3)$ & $0(0.0)$ & \\
\hline
\end{tabular}

In the study who underwent open repair it was observed that intraoperative complications i.e. Haemorrhages and Bowel injury were $16.7 \%$ and $3.3 \%$ respectively. Whereas in Laparoscopic repair group it was observed that $26.7 \%$ of subjects had haemorrhages and none of the patients had bowel injury. This observation was not statistically significant. ( $p$ value 0.411).

Table 4: Comparison of Mean Duration of Surgery between Open and Laparoscopic groups.

\begin{tabular}{|c|c|c|c|}
\hline Variables & $\begin{array}{c}\text { Open (n=30) } \\
\text { Mean (SD) }\end{array}$ & $\begin{array}{c}\text { Laparoscopic } \\
(\mathbf{n = 3 0}) \text { Mean } \\
\text { (SD) }\end{array}$ & $\begin{array}{c}\mathbf{P} \\
\text { Value }\end{array}$ \\
\hline Duration of Surgery (in min) & $75.8(30.7)$ & $77.3(22.4)$ & 0.830 \\
\hline
\end{tabular}

In our study we observed that the mean duration of surgery in open group was $75.8+/-30.7$ min and in laparoscopic group was $77.3+/-22.4$ min. Both the groups didn't differ with respect the duration of surgery.

Table 5: Comparison of Mean Duration of Return to work between Open and Laparoscopic Surgery.

\begin{tabular}{|c|c|c|c|}
\hline Variables & $\begin{array}{c}\text { Open } \\
(\mathbf{n = 3 0}) \\
\text { Mean (SD) }\end{array}$ & $\begin{array}{c}\text { Laparoscopic } \\
(\mathbf{n = 3 0 )} \text { Mean } \\
\text { (SD) }\end{array}$ & $\begin{array}{c}\mathbf{P} \\
\text { Value }\end{array}$ \\
\hline $\begin{array}{c}\text { Duration of Return to normal (in } \\
\text { Days) }\end{array}$ & $24.8(6.5)$ & $11.2(3.5)$ & $<\mathbf{0 . 0 0 1}$ \\
\hline
\end{tabular}

In our study we observed that mean duration of time taken to return to work (RTW) was $24.8+/-65$ and $11.2+/-3.5$ days in open and laparoscopic groups respectively. This observation was statistically significant with $\mathrm{p}$ value $<0.001$.

\section{Discussion}

Hernias are one of the common presentations in any surgical clinic, of which ventral hernias comprise second most common variety. Various types of surgical procedures have been described in the past for repair of ventral hernias, among all, mesh repair is the most accepted and $\mathrm{f}$ easible technique worldwide. Laparoscopic surgery is a major surgical advance, which through its minimal access nature enables a surgeon to give better outcomes to a patient.

Though laparoscopic surgery has been accepted as the gold standard in many other surgeries, its role in ventral hernia repair is still a matter of debate compared to the available open techniques. The relative advantages of laparoscopic and open ventral hernia repair are usually measured in terms of postoperative pain, intra operative and post-operative complications, duration of hospital stay, recovery and recurrence ${ }^{[6]}$.

In our study, mesh was placed intraperitoneally in all the patients who underwent laparoscopic repair 30 (100\%). Whereas in open group, in $17(56.7 \%)$ of subjects mesh was placed in Preperitoneal space, $9(30 \%)$ retromuscular, $2(6.7 \%)$ onlay and $2(6.7 \%)$ subjects had mesh placed in the intraperitoneal position. SSIn the present study we observed that intraoperatively $5(16.7 \%)$ in open group and $8(26.7 \%)$ in laparoscopic group had hemorrhage, whereas bowel injury was seen in $1(3.3 \%)$ patient in open group and none seen in laparoscopic group.

In our study, though not significant statistically we observed that the mean duration of surgery was found to be slightly more in laparoscopic group 77.3 minutes compared to open group 75.8 minutes. In an RCT by Holzman et al. ${ }^{[7]}$ mean duration of surgical procedure were 98 and 128 minutes respectively. Lomanto et al. ${ }^{[8]}$ study showed that mean duration of surgery was 93.3 and $90.6 \mathrm{~min}$ in open and laparoscopic groups respectively. And the mean duration of operative procedure was $75 \mathrm{~min}$ for open and $86 \mathrm{~min}$ for laparoscopic groups according to Misra et al. ${ }^{[9]}$ McGreevy et al. ${ }^{[10]}$ also showed similar findings.

\section{Conclusion}

- In this study mesh was placed in intraperitoneally in all laparoscopic groups. And in open group preperitoneal was the most common position (56.7\%), followed by retromuscular $(30 \%)$ where onlay and intraperitoneal mesh was placed in $6.7 \%$ of subjects each.

- In our study Physiomesh was used in all laparoscopic repairs intraperitoneally, and polypropylene mesh in different layers was used in open procedures.

- In this study we observed that, in terms of intraoperative complications, there was no statistically significant difference between two groups. Total $27 \%$ of patients had intraoperative hemorrhage, $16 \%$ in open and $27 \%$ in laparoscopic groups. 1 subject in open group had intraoperative bowel injury, none had it in laparoscopic group.

\section{References}

1. Sir Astley Paston Cooper, the Anatomy and Surgical Treatment of Inguinal and Congenital Hernia, Cox, London, 1804.

2. Mishra RK. Text book of laparoscopic hernia, $2^{\text {nd }}$ edition www.laparoscopyhospital.com 2009.

3. Norman S Williams, Christopher JK Bulstrode, Ronan O' Connell P. Bailey and Love's Short Practice of Surgery: Abdominal wall, hernia and umbilicus. 26. Boca Raton: CRC Press 2013.

4. Mark A Malangoni, Michael J Rosen. Sabiston Textbook of Surgery. Hernias. 19. Philadelphia: Elsever 2012.

5. Neal E, Seymour, Robert L. bell. Schwartz's principles and surgery: Abdominal wall, omentum, mesentry and retro peritoneum. 9. United states: McGraw Medical Hill; 2010.

6. LeBlanc KA, Booth W V., Whitaker JM, Bellanger DE. Laparoscopic incisional and ventral Herniorrhaphy in 100 patients. American Journal of Surgery. 2000. p. 193-7. Holzman MD, Purut CM, Reintgen K et al. Laparoscopic ventral and incisional Hernioplasty. Surg Endosc 1997; 11:32-5.

7. Lomanto D, Iyer SG, Shabbir A, Cheah WK. Laparoscopic versus open ventral hernia mesh repair: a prospective study. SurgEndosc 2006;20:1030-1035.

8. Misra MC, Bansal VK, Kulkarni MP, Pawar DK. Comparison of laparoscopic and openrepair of incisional and primary ventral hernia: results of a prospective randomized study.

9. McGreevy JM, Goodney PP, Birkmeyer CM, Finlayson SR, Laycock WS, Birkmeyer JD. A prospective study comparing the complication rates between laparoscopic and open ventral hernia repairs. Surg Endosc 2003;17:1778-1780. 